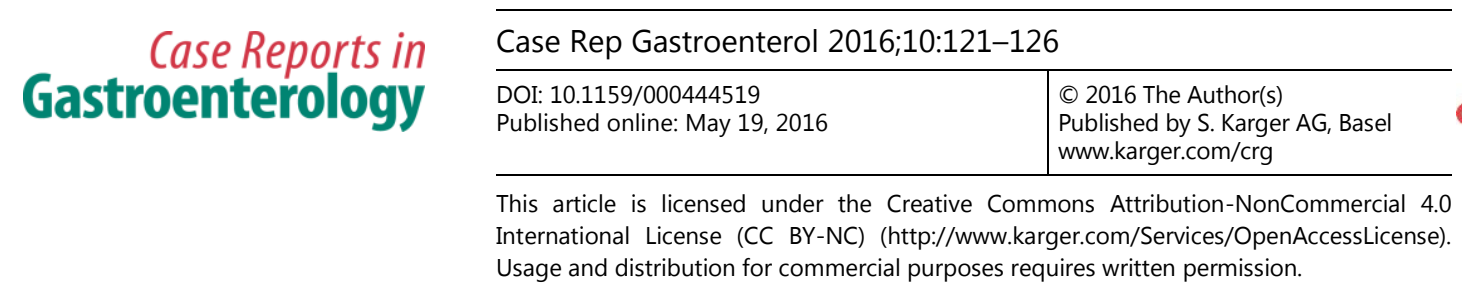

\title{
Gastric Perforation by Ingested Rabbit Bone Fragment
}

\author{
Giulio Gambaracci $^{\mathrm{a}} \quad$ Eleonora Mecarini $^{\mathrm{a}} \quad$ Maria Silvia Franceschini $^{\mathrm{b}}$ \\ Michele Scialpi ${ }^{\mathrm{a}}$ \\ ${ }^{a}$ Department of Surgical and Biomedical Sciences, Division of Radiology 2, Perugia \\ University, Santa Maria della Misericordia Hospital, Perugia, Italy; ${ }^{b}$ Department of Surgical \\ and Biomedical Sciences, Division of Radiology 1, Santa Maria della Misericordia Hospital, \\ Perugia, Italy
}

\section{Keywords}

Foreign body $\cdot$ Stomach $\cdot$ Perforation $\cdot$ Rabbit $\cdot$ Bone fragment $\cdot$ Ingestion

\begin{abstract}
The majority of accidentally ingested foreign bodies is excreted from the gastrointestinal (GI) tract without any complications. Sometimes sharp foreign bodies - like chicken and fish bones - can lead to intestinal perforation and may present insidiously with a wide range of symptoms and, consequently, different diagnoses. We report the case of a 59-year-old woman presenting with fever and a 1-month history of vague abdominal pain. Computed tomography $(\mathrm{CT})$ showed the presence of a hyperdense linear image close to the gastric antrum surrounded by a fluid collection and free peritoneal air. At laparotomy, a 4-cm rabbit bone fragment covered in inflamed tissue was detected next to a gastric wall perforation. Rabbit bone fragment ingestion, even if rarely reported, should not be underestimated as a possible cause of GI tract perforation.

(C) 2016 The Author(s)

Published by S. Karger AG, Basel
\end{abstract}

\section{Introduction}

Foreign body ingestion in adults passes through the gastrointestinal (GI) tract uneventfully within a week in $80 \%$ of cases, and $<1 \%$ of patients develop complications including

KARGER 
visceral wall perforation [1-3]. Long, narrow, or pointed foreign bodies can be associated with a higher risk of impaction, as well as complications such as perforation [4].

Intra-abdominal foreign body perforations of the GI tract have been reported in all segments; most frequently, in regions of acute angulation such as the rectosigmoid or the ileocecum, or proximally to a site of pathologic narrowing or obstruction $[1,5]$.

Foreign body perforation of the GI tract has a wide spectrum of clinical presentations, which can be either acute or chronic [6]. In the former, GI perforation secondary to foreign body ingestion may present as odynophagia or abdominal pain. However, perforations of the stomach, duodenum and large bowel, due to their thicker mucosal walls, may present in a more insidious manner, including hemorrhage, appendicitis, bowel obstruction and even ureteric colic [7-10]. With these varied and nonspecific clinical presentations it is not surprising that a definite preoperative diagnosis is rare [6].

The types of accidentally ingested foreign bodies directly depend on dietary habits and vary according to the country, age, and cognitive status of the patient [1]. Gastric perforation secondary to the ingestion of fish or chicken bones and shell fragments have been generally reported, but only a few cases caused by rabbit bone fragments are known [11,12].

We report the case of a gastric perforation caused by the ingestion of a rabbit bone fragment to raise awareness of a rare but potential cause of GI lesion.

\section{Case Presentation}

A 59-year-old woman was admitted to the emergency department with a 1-month history of nausea and vague, mild epigastric pain. On physical examination, she was conscious with mild pyrexia and an area of tenderness in the epigastric region. Her past medical history was positive for hypertension and eye surgery.

A previous abdominal ultrasonography (US) was unremarkable with the exception of gallbladder gallstones. The patient was treated by her general practitioner with a 10-day course of broad-spectrum antibiotics, with mild benefits. Laboratory investigations revealed raised inflammatory markers (ESR $59 \mathrm{~mm} / \mathrm{h}$, WBC $16.09 \times 10^{3} \mu \mathrm{l}$ ) with no other main abnormalities. Electrocardiography, performed to exclude myocardial infarction, was normal.

An abdominal US confirmed the presence of gallbladder gallstones, however, without signs of acute cholecystitis (fig. 1). The US also revealed the presence of an ill-defined hypoechogenic lesion, next to the gastric antrum (fig. 2).

Precontrast and contrast-enhanced computed tomography (CT) scans showed a 4-cm hyperdense linear image surrounded by an ill-defined heterogeneous fluid collection with peripheral enhancement, suggestive of a perigastric abscess with an enclosed foreign body (fig. 3).

Explorative laparotomy revealed a bone fragment embedded within a purulent fluid collection between the anterior gastric margin and the abdominal wall. The specimen was removed and sent for histological analysis.

Following the drainage of thick liquid pus material, a gastric discontinuity was noted, and a partial gastrectomy was completed along the greater curvature of the stomach. A cholecystectomy was also performed and a drainage was placed in the sub-liver space.

The postoperative course was smooth and uneventful. The patient was treated with intravenous antibiotics and discharged in good clinical conditions on the 9th postoperative day, with normal blood biochemical examination (WBC 9,300 × 1030 $\mu$ l, HGB $11.8 \mathrm{~g} / \mathrm{dl}$ ). 
Histopathological examination of the omental-gastric specimens revealed the presence of an animal bone fragment surrounded by severely inflamed tissue.

During a careful reconstruction of the case history, the patient recalled she had been eating rabbit meat the day before her pain started.

\section{Discussion}

In the adult population, perforation of the GI tract by ingested foreign bodies is usually secondary to involuntary accidental ingestion and is frequently caused by foreign bodies included in meals [1]. The main predisposing factor for their ingestion is the use of dentures that could reduce the sensory feedback of the palate. Other factors include very young and old age, cognitive impairment, history of psychosis, being fast eaters, and alcohol or drug abuse $[1,2]$.

A foreign body that perforates the wall of the GI tract may take several different possible courses, including lying in the visceral lumen at the site of perforation, or passing through the wall and migrating to a distal organ [13]. For this reason, too, the preoperative diagnosis of stomach perforation caused by ingested foreign bodies tends to be insidious. In fact, the clinical presentation can be elusive because bone fragments can cause omental reactions mimicking tumors, and most patients do not remember the ingestion of specific foreign bodies $[5,7,8]$.

The use of plain radiography for the detection of nonmetallic ingested foreign bodies is unreliable because large soft-tissue masses and fluid can obscure the minimal calcium content of the bone, particularly in altered or obese patients [6]. In addition, because the foreign body is impacted gradually and the perforation is covered with fibrin, it is difficult to find free pneumoperitoneum [14]. Therefore, the use of a CT scan should be preferred and will usually demonstrate a linear calcified lesion surrounded by an area of inflammation [6]. Nevertheless, the accuracy of CT is limited by the lack of observer awareness, and a high index of suspicion must be maintained to reach a correct diagnosis [6].

The types of accidentally ingested foreign bodies vary from country to country and directly depend on dietary habits. Gastric perforation secondary to ingestion of shell fragments and fish or chicken bones have been widely reported [1], but only a few cases caused by rabbit bone fragments are known [11,12]. This low frequency is probably related to the lower worldwide consumption of this type of meat [15].

The ingestion of rabbit bone fragments, even if rarely reported, should not be overlooked as a possible cause of gastric perforation and abscess formation in patients with unexplained abdominal pain, especially in countries, such as Italy, that are reported to have one of the highest consumption rate of rabbit meat per inhabitant [15].

\section{Statement of Ethics}

The authors have no ethical conflicts to disclose. 


\section{Case Reports in \\ Gastroenterology}

(C) 2016 The Author(s). Published by S. Karger AG, Basel www.karger.com/crg

Gambaracci et al.: Gastric Perforation by Ingested Rabbit Bone Fragment

\section{Disclosure Statement}

The authors declare that there are no conflicts of interest regarding the publication of this article.

\section{References}

1 Goh BK, Chow PK, Quah HM, Ong HS, Eu KW, Ooi LL, et al: Perforation of the gastrointestinal tract secondary to ingestion of foreign bodies. World J Surg 2006;30:372-377.

2 Velitchkov NG, Grigorov GI, Losanoff JE, Kjossev KT: Ingested foreign bodies of the gastrointestinal tract: retrospective analysis of 542 cases. World J Surg 1996;20:1001-1005.

McCanse DE, Kurchin A, Hinshaw JR: Gastrointestinal foreign bodies. Am J Surg 1981;142:335-337.

-4 Chung YS, Chung YW, Moon SY, et al: Toothpick impaction with sigmoid colon pseudodiverticulum formation successfully treated with colonoscopy. World J Gastroenterol 2008;14:948-950.

-5 Ricci G, Campisi N, Capuano G, et al: Liver abscess and pseudotumoural gastric lesion caused by chicken bone perforation: laparoscopic management. Case Rep Surg 2012;2012:791857.

6 Goh BK, Tan YM, Lin SE, et al: CT in the preoperative diagnosis of fish bone perforation of the gastrointestinal tract. AJR Am J Roentgenol 2006;187:710-714.

-7 Williams HE, Khokhar AA, Rizvi M, Gould S: Gastric perforation by a foreign body presenting as a pancreatic pseudotumour. Int J Surg Case Reports 2014;5:437-439.

- Joglekar S, Rajput I, Kamat S, Downey S: Sigmoid perforation caused by an ingested chicken bone presenting as right iliac fossa pain mimicking appendicitis: a case report. J Med Case Rep 2009;3:7385.

-9 Maleki M, Evans WE: Foreign-body perforation of the intestinal tract: report of 12 cases and review of the literature. Arch Surg 1970;101:474-477.

10 Ginzburg L, Beller AJ: The clinical manifestations of non-metallic perforating intestinal foreign bodies. Ann Surg 1927;86:918-939.

11 Ward-Mcquaid JN: Perforation of the intestine by swallowed foreign bodies, with a report of two cases of perforation by rabbit bones. Br J Surg 1952;39:349-351.

12 Tallón Aguilar L, Bernal Moreno DA, López Porras M, Marín Gómez LM, Pareja Ciuró F: Foreign bodies as infrequent cause of liver abscess. Rev Esp Enferm Dig 2011;103:334-335.

13 Kim JS, Kim HK, Cho YS, et al: Extraction and clipping repair of a chicken bone penetrating the gastric wall. World J Gastroenterol 2008;14:1955-1957.

14 Cho HJ, Kim SJ, Lee SW, Moon SW, Park JH: Pseudotumor of the omentum associated with migration of the ingested crab-leg. J Korean Med Sci 2012;27:569-571.

15 Colin M, Lebas F: Production et consommation de viande de lapin dans le monde. Communication aux 6es Journées de la recherche cunicole en France, 6-7 Déc. 1994. 


\section{Case Reports in Gastroenterology

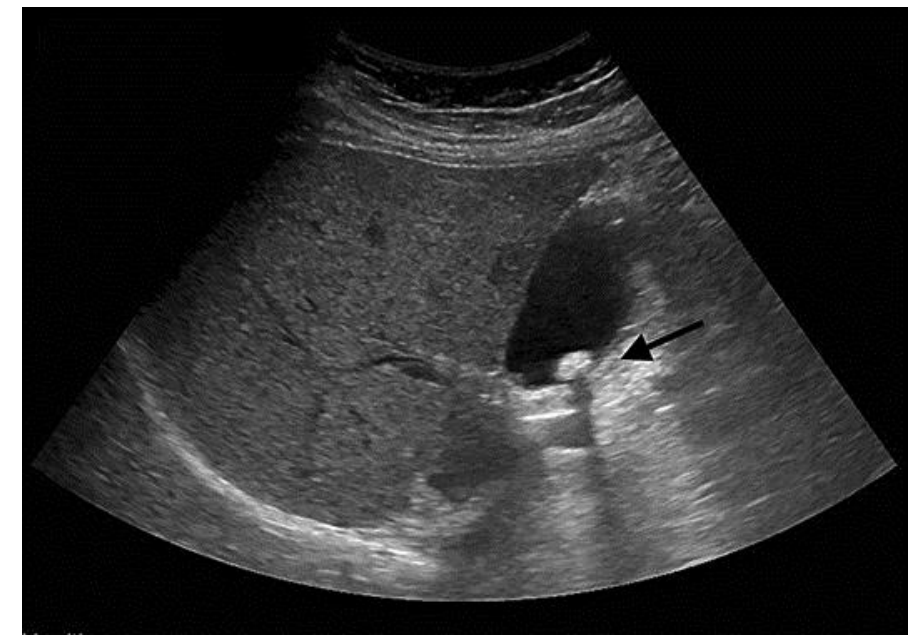

Fig. 1. Axial ultrasonographic image demonstrates a gallbladder gallstone (black arrow) without signs of acute cholecystitis.

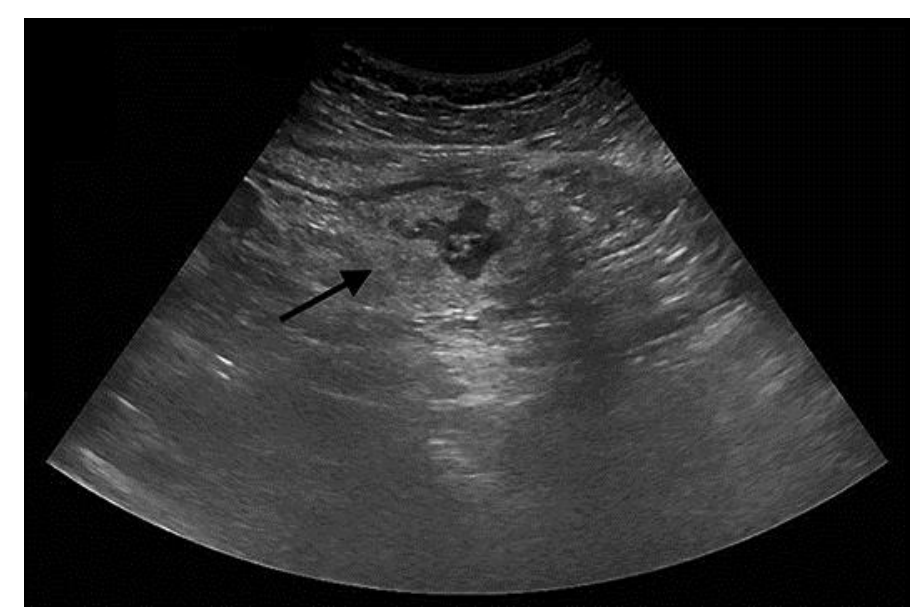

Fig. 2. Axial ultrasonographic image shows the presence of an ill-defined hypoechogenic lesion (black arrow) next to the gastric antrum. 


\section{Case Reports in Gastroenterology

\begin{tabular}{l|l}
\hline Case Rep Gastroenterol 2016;10:121-126 \\
\hline $10.1159 / 000444519$ & $\begin{array}{l}\text { @ 2016 The Author(s). Published by S. Karger AG, Basel } \\
\text { www.karger.com/crg }\end{array}$ \\
\hline
\end{tabular} \\ Gambaracci et al.: Gastric Perforation by Ingested Rabbit Bone Fragment}

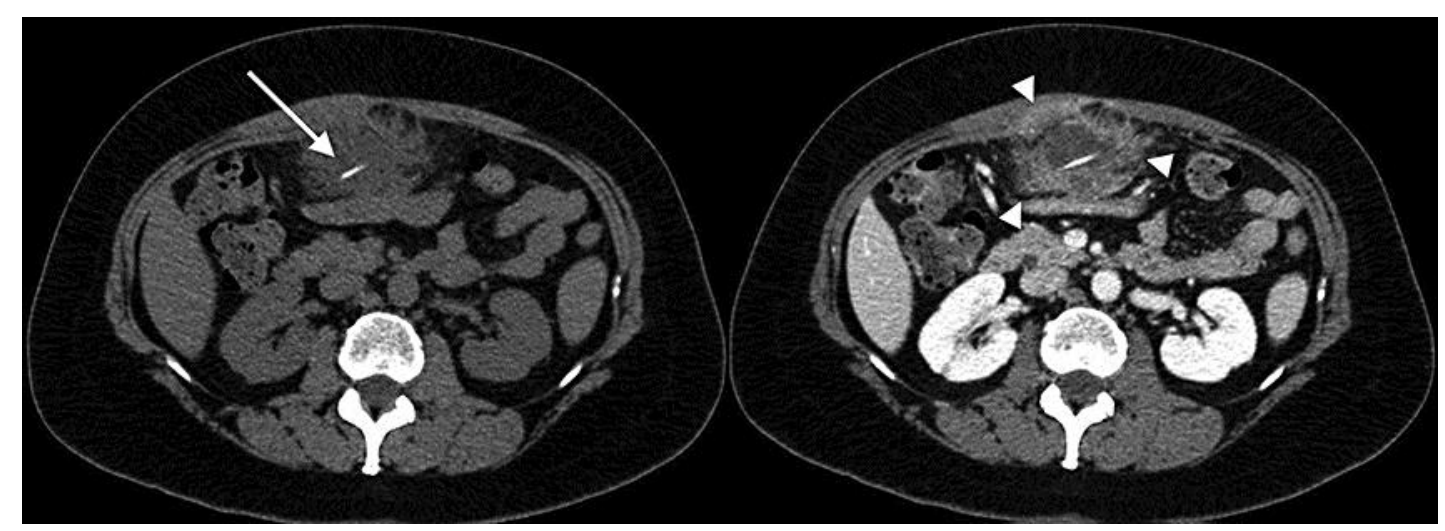

Fig. 3. Axial pre- and postcontrast CT of the upper abdomen revealing a hyperdense linear image (white arrow) enclosed in an abscess (white arrowheads) in contact with abdominal and gastric walls. 